\title{
Original
}

\section{Long-Term Study of Neonatal Examination for Congenital Dislocation of the Hip}

\author{
Susumu SaIto, Yoshikatu Kuroki, Hirofumi OHgiYa, \\ Ryushi Marutani and Ken Yamano
}

\begin{abstract}
In treating congenital dislocation of the hip, the importance of early screening should be emphasized. We summarized the results of orthopaedic examination for neonates who were born from Oct. 1977 to Dec. 1994. During this time 11370 babies were born in the maternity ward of Showa University Fujigaoka Hospital. A total of 8886 babies (78.2\%) were examined, including 4506 male babies and 4380 female babies. Regarding the click sign, in which the instability of the hip joint can be felt by allowing the femoral head to slip in and out of the joint cavity, Ortolani's click sign was positive in 6 cases (6 joints) and Barlow's click sign was positive in 8 cases (10 joints). Of the cases tested by Barlow's click sign, $0.1 \%$ were positive. In these cases one was affected with Larsen's syndrome. Three cases that tested negative using the click sign were found to be dislocated at the follow-up time during infancy. In the click sign-positive cases, plaster cast fixation was performed in two patients, the remaining five patients were treated by a Pavlik harness and one patient was treated by abducted diaper. From follow-up examinations at an average age of 5.4 years satisfactory results were obtained in seven cases; only one case treated by plaster cast fixation showed bilateral slight aseptic necrosis of the femoral head. Although click sign-positive cases have been decreased due to primary prophylaxis from birth, the neonatal examination is essential for detecting the dislocation of the hip in early life.
\end{abstract}

Key words: neonatal examination, congenital dislocation of the hip, click sign

\section{Introduction}

Due to the prophylaxis for congenital dislocation of the hip, the occurrence of dislocations has been reportedly decreased ${ }^{1,2)}$.

Here we summarize the results of the 17 years of neonatal examinations at Showa University Fujigaoka Hospital and discuss the significance of examination of hip dislocation ${ }^{3)}$.

\section{Materials and Methods}

We examined new born babies once a week, who were born at Showa University Fujigaoka Hospital from Oct. 1977 to Dec. 1994, within the first week after birth. At such an examination, first the posture, deformities and anomalies of neonates were observed. Secondly, the limitation of abduction of the hip and Ortolani's ${ }^{4)}$ and Barlow's click sign ${ }^{5)}$ were $^{2}$ investigated.

Department of Orthopaedic Surgery, Showa University Fujigaoka Hospital, 1-30 Fujigaoka, Aoba-ku, Yokohama 227, Japan. 
Regarding the usage of a diaper, from 1977 babies were fitted in the hip abducted position.

\section{Results}

1) Number and frequency of examination

A total of 8886 babies (4506 males and 4380 females) among 11370 births (78.2\%) were examined during this period (Table 1).

Examination was carried out within a week after birth, and mostly on the third day after birth (Table 2).

Table 1. Number of births, number of examinations and frequency of examination at Showa University Fujigaoka Hospital (Oct. 1977-Dec. 1994).

\begin{tabular}{rrrrrr}
\hline \multirow{2}{*}{ Year } & No. of births & \multicolumn{3}{c}{ No. of examinations } & $\begin{array}{c}\text { Frequency of } \\
\text { examinations }\end{array}$ \\
\hline 1977 & 108 & Male & Female & Total & \% \\
\hline 1978 & 470 & 212 & 35 & 68 & 63.0 \\
1979 & 560 & 215 & 201 & 416 & 74.6 \\
1980 & 684 & 271 & 258 & 529 & 77.3 \\
1981 & 667 & 269 & 242 & 511 & 76.6 \\
1982 & 609 & 193 & 234 & 527 & 70.1 \\
1983 & 660 & 268 & 243 & 511 & 77.4 \\
1984 & 637 & 258 & 236 & 494 & 77.6 \\
1985 & 687 & 276 & 251 & 527 & 76.7 \\
1986 & 701 & 281 & 306 & 587 & 83.7 \\
1987 & 674 & 259 & 278 & 537 & 79.7 \\
1988 & 592 & 250 & 243 & 493 & 83.3 \\
1989 & 635 & 266 & 255 & 521 & 82.0 \\
1990 & 732 & 303 & 276 & 579 & 79.0 \\
1991 & 775 & 318 & 276 & 594 & 76.6 \\
1992 & 758 & 289 & 306 & 595 & 78.5 \\
1993 & 105 & 272 & 267 & 539 & 76.5 \\
1994 & 716 & 273 & 292 & 565 & 79.0 \\
\hline Total & 11370 & 4506 & 4380 & 8886 & 78.2 \\
\hline
\end{tabular}

Table 2. Date of examination.

\begin{tabular}{cc}
\hline Date of exam. & No. of exam. \\
\hline 1 st day & 967 \\
2 & 1588 \\
3 & 1610 \\
4 & 1503 \\
5 & 1349 \\
6 & 1216 \\
7 & 380 \\
Others & 273 \\
\hline Total & 8886 \\
\hline
\end{tabular}


Table 3. Intra-uterine position and type of delivery.

\begin{tabular}{lrr} 
& Numbers & $\%$ \\
\hline Vertex delivery & 7643 & 86.0 \\
Vertex presentation, caesarian section & 925 & 10.4 \\
Breech delivery & 158 & 1.8 \\
Breech presentation, caesarian section & 160 & 1.8 \\
\hline Total & 8886 & \\
\hline
\end{tabular}

Table 4. Orthopaedic disorders other than congenital dislocation of the hip.

\begin{tabular}{|c|c|c|}
\hline \multirow[t]{15}{*}{ Congenital: } & Calcaneo valgus foot & 37 \\
\hline & Varus position foot & 14 \\
\hline & Down syndrome & 6 \\
\hline & Poly and syndactylies & 6 \\
\hline & Camptodactyly & 5 \\
\hline & Bracydactylies & 2 \\
\hline & Floating finger & 2 \\
\hline & Spina bifida & 1 \\
\hline & Femoral defect & 1 \\
\hline & Knee dislocation & 1 \\
\hline & Funnel breast & 1 \\
\hline & Pterygium colli & 1 \\
\hline & Major pectoralis defect & 1 \\
\hline & Constriction band syndrome & 1 \\
\hline & Larsen syndrome & 1 \\
\hline & Total & 80 \\
\hline \multirow[t]{4}{*}{ Aquired: } & Clavicular fracture & 10 \\
\hline & Birth palsy & 5 \\
\hline & Humeral fracture & 1 \\
\hline & Total & 16 \\
\hline
\end{tabular}

\section{2) Type of delivery}

Of the deliveries, $86.0 \%$ were vertex delivery and $10.4 \%$ were vertex presentation delivered by caesarian section; $1.8 \%$ were assisted breech delivery and $1.8 \%$ were breech presentation delivered by caesarian section. The body weight at birth was from $1220 \mathrm{~g}$ to $4970 \mathrm{~g}$, with an average birth weight of $3117.4 \mathrm{~g}$ (Table 3).

3) Other orthopaedic disorders

The other orthopaedic disorders that were observed were 37 valgus feet, 14 varus position feet, 6 Down's syndromes, 6 poly and syndactylies, 5 camptodactylies, 2 branchydactylies, 2 floating fingers, one spina bifida, one congenital femoral defect, one congenital knee dislocation, one funnel breast, one pterygium colli, one congenital major pectoralis defect, one constriction band syndrome and one Larsen's syndrome ${ }^{6)}$ (Table 4). 
Table 5. Click-positive cases.

\begin{tabular}{|c|c|c|c|c|c|c|c|}
\hline Sex & Birthday & $\begin{array}{c}\text { Birth } \\
\text { weight }\end{array}$ & $\begin{array}{l}\text { Birth } \\
\text { order }\end{array}$ & $\begin{array}{l}\text { Intrauterine posture and } \\
\text { type of delivery }\end{array}$ & $\begin{array}{l}\text { Examination } \\
\text { day }\end{array}$ & \multicolumn{2}{|c|}{ Click sign } \\
\hline $\mathbf{F}$ & 1979.2.25 & 2790 & $1 \mathrm{st}$ & vertex & 5 & $\begin{array}{l}\text { Ortolani } \\
\text { Barlow }\end{array}$ & $\begin{array}{l}\text { R. }+ \\
\text { R. }+ \text {, L. }+\end{array}$ \\
\hline $\mathbf{M}$ & 1980.8 .4 & 1220 & $1 \mathrm{st}$ & vertex, caesarian section & 7 & $\begin{array}{l}\text { Ortolani } \\
\text { Barlow }\end{array}$ & $\begin{array}{l}\text { R. }+ \\
\text { R. }+\end{array}$ \\
\hline $\mathrm{F}$ & 1981.1.15. & 2640 & 2nd & vertex & 7 & $\begin{array}{l}\text { Ortolani } \\
\text { Barlow }\end{array}$ & - \\
\hline $\mathrm{F}$ & 1982.1.11. & 3980 & $1 \mathrm{st}$ & vertex & 6 & $\begin{array}{l}\text { Ortolani } \\
\text { Barlow }\end{array}$ & $\begin{array}{l}\text { L. }+ \\
\text { L. }+\end{array}$ \\
\hline $\mathrm{F}$ & 1983.4.25. & 3380 & $1 \mathrm{st}$ & vertex & 4 & $\begin{array}{l}\text { Ortolani } \\
\text { Barlow }\end{array}$ & $\begin{array}{l}\text { L. }+ \\
\text { L. }+\end{array}$ \\
\hline $\mathrm{F}$ & 1987.10.31. & 3650 & $1 \mathrm{st}$ & vertex & 5 & $\begin{array}{l}\text { Ortolani } \\
\text { Barlow }\end{array}$ & $\begin{array}{l}\text { L. }+ \\
\text { L. }+\end{array}$ \\
\hline $\mathbf{F}$ & 1990.10 .26 & 3166 & $1 \mathrm{st}$ & breech, caesarian section & 1 & $\begin{array}{l}\text { Ortolani } \\
\text { Barlow }\end{array}$ & $\begin{array}{l}\text { L. }+ \\
\text { L. }+\end{array}$ \\
\hline $\mathbf{F}$ & 1992.6.19. & 3580 & $1 \mathrm{st}$ & breech, caesarian section & 7 & $\begin{array}{l}\text { Ortolani } \\
\text { Barlow }\end{array}$ & $\overline{\text { R. }+ \text {, L. }+}$ \\
\hline
\end{tabular}

Table 6. Comparison of click sign-positive cases from 1977 to 1994.

\begin{tabular}{cccc}
\hline Examination period & No. of exam. & No. of click positive & Frequency of click pos. \% \\
\hline Oct. 1977 Dec. 1985 & 3876 & 5 & 0.13 \\
Jan. 1986 Dec. 1994 & 4910 & 3 & 0.06 \\
\hline
\end{tabular}

\section{4) Click sign}

Ortolani's click sign (the examination technique reported by Ortolani ${ }^{4)}$ ) was positive in 6 cases, $0.1 \%$ (6 joints) among 8886 neonates. Barlow's click sign ${ }^{5)}$ was positive in 8 cases, $0.1 \%$ (10 joints) in 8886 neonates: in one male baby and in 7 female babies. One male neonate was affected with Larsen's syndrome (Table 5). Of these 8 babies, the posture of birth was vertex position in 6 and in breech position in 2. Three of these were delivered by caesarian section: 7 were first born babies and one was a second born baby.

Three babies were born from January to March, 2 from April to June, one from July to September, and 2 from October to December. Five babies were affected in the left hip, 2 in the right hip and 2 in both hips. The click sign positivity was observed from 1979 to 1983, and in 1987, 1990 and 1992. During the first 9 years, from 1977 to 1985,5 of 3876 babies $(0.13 \%)$ tested as click sign-positive; in the second 9-year period, from 1986 to 1994, 3 of $4910(0.06 \%)$ tested as click sign positive. Compared to the first 9 years, the number of click sign-positive cases decreased by $0.07 \%$ (Table 6).

5) Dislocations from click-negative cases

Three dislocations were recognized in the click negative cases during the follow-up period in infancy. One of these cases was found to be congenital muscular dystrophy (Table 7).

6) Treatment

Concerning click sign-positive cases, plaster cast fixation was performed in two cases. The 
Table 7. Dislocations found later in click negative cases at the neonatal examination.

\begin{tabular}{|c|c|c|c|c|c|c|c|}
\hline Sex & Birth day & $\begin{array}{l}\text { Birth } \\
\text { weight }\end{array}$ & $\begin{array}{l}\text { Birth } \\
\text { order }\end{array}$ & $\begin{array}{c}\text { Intrauterine } \\
\text { posture, } \\
\text { type of } \\
\text { delivery }\end{array}$ & $\begin{array}{l}\text { Examination } \\
\text { day }\end{array}$ & $\begin{array}{l}\text { Dislocation } \\
\text { diagnosed age }\end{array}$ & Treatment \\
\hline $\mathbf{F}$ & 1980.12.10. & 3560 & $2 n d$ & vertex & 3 & $5 \mathrm{M}$ & Pavlik harness \\
\hline \multicolumn{8}{|c|}{ Congenital dystrophy } \\
\hline F & 1981.12 .2 & 2940 & $2 \mathrm{nd}$ & vertex & 3 & $2 \mathrm{M}$ & Pavlik harness \\
\hline $\mathrm{F}$ & 1992.12 .14 & 3168 & $3 r d$ & vertex & 2 & $2 \mathrm{M}$ & $\begin{array}{l}\text { Pavlik harness } \\
\rightarrow \text { Plaster cast }\end{array}$ \\
\hline
\end{tabular}

Table 8. Treatment of click-positive cases.

\begin{tabular}{|c|c|c|c|}
\hline Case & Treatment & Follow-up period & Result \\
\hline 1 & Pavlik harness & $8 \mathrm{M}$ & Good \\
\hline 2 & Plaster cast & $14 \mathrm{Y} 4 \mathrm{M}$ & Good \\
\hline 3 & Pavlik harness & $3 \mathrm{Y} \quad 1 \mathrm{M}$ & Good \\
\hline 4 & Pavlik harness & $11 \mathrm{Y} 8 \mathrm{M}$ & Good \\
\hline 5 & Pavlik harness & $5 \mathrm{Y} 4 \mathrm{M}$ & Good \\
\hline 6 & Pavlik harness & $4 \mathrm{Y} 6 \mathrm{M}$ & Good \\
\hline 7 & Abducted diaper & $1 \mathrm{Y} 6 \mathrm{M}$ & Good \\
\hline 8 & Pavlik harness $\rightarrow$ Plaster cast & $2 \mathrm{Y} 6 \mathrm{M}$ & aseptic necrosis \\
\hline
\end{tabular}

other five cases were treated using a Pavlik harness and one case was treated using abducted diapers. All were satisfactory except one plaster cast fixation case which showed slight aseptic necrosis of the femoral head in both hips (follow-up period: from 8 months to 14 years and 4 months, average 5 years 5 months) (Table 8).

\section{Discussion}

\section{1) Frequency of examination}

In our hospital normal delivery babies are discharged about 6 to 7 days after birth. Thus the frequency of a once a week examination was $78.2 \%$.

2) The click sign test as assessed by Barlow's technique

Barlow's test is more accurate to reveal an unstable dislocatable hip than Ortolani's test. It is meaningful to do long-term examinations rather than numerous examinations over a short period.

3) Frequency of occurrence of the click sign-positive cases

The frequency of click sign-positive cases tested by Barlow's click sign was $0.1 \%$ ( 8 cases, 10 joints). Compared with the term from Oct. 1977 to Dec. 1985 and the term Jan. 1986 to Dec. 1994, the occurrence of the click sign-positive cases in the period of the first half was $0.13 \%$ ( 5 positive cases of 3876 babies) and that of the second half was $0.06 \%$ ( 3 positive cases of 4910 babies). The frequency of click-positive cases of the later half was decreased. The following is the incidence reported from other studies: Yamamuro ${ }^{7}$ : $1.6 \%$ ( 115 cases of about 1200 babies), Yamada ${ }^{8)}: 0.72 \%$ (60 cases of 8337 babies), Ishida $^{1)}: 2.75 \%$ (54 of 1967) by rolled style diaper, $0.28 \%$ ( 9 of 3224) by hip abducted 
Table 9. Reports of click sign-positive cases in neonatal examination.

\begin{tabular}{rlccl}
\hline Year & Author & $\begin{array}{c}\text { No. of } \\
\text { examination }\end{array}$ & $\begin{array}{c}\text { No. of click } \\
\text { sign positive }\end{array}$ & $\begin{array}{c}\text { Frequency of click } \\
\text { sign positive \% }\end{array}$ \\
\hline 1970 & Yamada & 8337 & 60 & 0.72 \\
1972 & Yamamuro & 7200 & 115 & 1.6 \\
1978 & Akashi & 2589 & 4 & 0.15 \\
1980 & Ishida & 1967 & 54 & 2.75 (rolled diaper) \\
& & 3224 & 9 & 0.28 (hip abd. diaper) \\
1980 & Ogiwara & 8554 & 143 & 1.67 (Year 1964 1975) \\
& & 2837 & 15 & 0.53 (Year 1976 1979) \\
1985 & Iwasaki & 19373 & 78 & 0.4 \\
1995 & Present study & 8886 & 8 & 0.1 \\
\hline
\end{tabular}

style diaper, Ogiwara ${ }^{9}: 1.67 \%$ (143 of 8554, from 1967 to 1975), $0.53 \%$ (15 of 2837 , from 1962 to 1979), Iwasaki ${ }^{2)}$ et al.: $0.40 \%$ (78 of 19373), Akashi ${ }^{10)}$ et al.: $0.15 \%$ (4 of 2589, from 1971 to 1982) (Table 9). Compared to these data the present result of $0.1 \%$ seemed low. Concerning the season of frequency of the click sign-positive cases, there were three cases from January to March, two from April to June, one from July to September and two from October to December. The frequency of click sign-positive cases was related to the birth season. Namely the incidence was high among the babies born in cold seasons. According to the birth order, the first born babies were 5 cases and second born was one case. Based on this result, the first born baby is thought to have a possibility of a higher occurrence of click positivity. But this is not necessarily true, as all cases did not always include multiple birth families. Concerning about the delivery style, 6 cases were delivered in the vertex position and 2 cases in the breech position. A positive click sign was noticed more often in the left hip than in the right hip.

4) Dislocations from click sign-negative cases

Three dislocations were observed in infancy which were not found in the neonatal examination. One of these was recognized to be congenital muscular dystrophy in infancy. Were all these cases unrecognized in the first examination? This is possibly the case when click sign was negative in neonate and then dislocation was visible in infancy due to the increase of limitation of abduction of the hip or by the unclearness of click sign under muscular disease.

5) The significance of the examination for congenital dislocation of the hip in neonates

Although neonatal examination was thought to be influenced throughout Japan, this examination has not been performed in all of the hospitals in Japan. It is a very hard task to perform neonatal examination for a long time period. To do this examination for a long time is very meaningful. It is also very important for the study of the epidemiology of congenital dislocation of the hip in order to know the incidence of click sign-positive cases overall in Japan and also to acknowledge the incidence change from year to year. Although primary prophylaxis of congenital dislocation of the hip has been influential and the click sign-positive rate has decreased, the orthopaedic examination continues to be important to determine dislocatable hips. Because the prognosis of dislocations found by neonatal examination is very good, the neonatal examination is significant. Although the incidence of click sign positivity is decreasing, and the significance of the neonatal examination 
is becoming weak, the chance for an orthopaedist to observe neonates is in itself very meaningful, in terms of observing possible new findings in babies.

\section{Conclusion}

1. We reported the results of orthopaedic examinations for neonates over an 18-year period and discussed the significance of this examination.

2. We performed the examination on 8886 cases of 11370 new born babies.

3. Ortolani's and Barlow's click sign test were performed. Ortolani's click sign was positive in 6 cases ( 6 joints), and Barlow's click sign was positive in 8 cases (10 joints). According to Barlow's click sign, the incidence of the positivity rate was $0.1 \%$.

4. Three dislocations were found later in infancy in cases which were click negative at the neonatal examination.

5. The results of treatment by Pavlik harness were all satisfactory but one bilateral dislocated case showed slight aseptic necrosis of the femoral head.

6. Although the occurrence of click sign-positive cases has been decreasing due to primary prophylaxis, the examination of neonates is still significant.

\section{Acknowledgements}

The author thanks Prof. Hidenosuke Araki and Prof. Yukimasa Notake for valuable advice and help in this study.

\section{References}

1) Ishida K: Prevention of congenital dislocation of the hip-History, proof, practice and prospect. Rinsho Seikei Geka, 15: 452-460 (1980) (in Japanese)

2) Iwasaki K, Suzuki R, Ikeda S, Yamamoto N, Matumoto $T$ and Yamada K: Results of neonatal examination of congenital dislocation of the hip for twelve years. Seikei Saigai Geka, 28: 49-54 (1985) (in Japanese)

3) von Rosen S: Diagnosis and treatment of congenital dislocation of the hip joint in the new-born. J. Bone Joint Surg [Br], 44: 284-291 (1962)

4) Ortolani M: The classic: Congenital hip dysplasia in the light of early and very early diagnosis. Clin Orthop, 119: 6-47 (1976)

5) Barlow TG: Early diagnosis and treatment of congenital dislocation of hip. J Bone Joint Surg [Br], 44: 291-301 (1962)

6) Marutani R, Saito S, Uchida $T$ and Kuroki Y: Two cases of congenital dislocation of the hip joint in Larsen syndrome. Seikei Saigai Geka, 31: 1473-1476 (1988) (in Japanese)

7) Yamamuro T: Congenital dislocation of the hip during the neonatal period. Nihon Seikei Geka Gakkaizasshi, 46: 695-711 (1972) (in Japanese)

8) Yamada K, Ogawa E, Imamura K, Tuchiya K, Yoshida M and Izawa Y: Congenital dislocation of the hip in new born babies. Rinsho Seikei Geka, 21: 589-598 (1970) (in Japanese)

9) Ogiwara K: Practice of the prophylaxis of C.D.H. Chubunippon Seikei Geka Saigai Geka Gakkaizasshi, 23: 1184-1185 (1980) (in Japanese)

10) Akashi $Y$, Ogata $M$, Tahara T, Yoshioka $Y$ and Fuji M: Environmental influence on the development of C.D.H.-Epidemiologic study in Wakayama prefecture. Chubunippon Seikei Geka Saigai Geka Gakkaizasshi, 21: 453-454 (1978) (in Japanese)

[Received January 27, 1995: Accepted March 14, 1995] 